\title{
Serotonin-Driven Long-Range Inhibitory Connections in the Cerebellar Cortex
}

\author{
Stéphane Dieudonné ${ }^{1}$ and Andréa Dumoulin² \\ 1Laboratoire de Neurobiologie, Centre National de la Recherche Scientifique Unité Mixte de Recherche 8544, and \\ ¿Laboratoire de Biologie Cellulaire de la Synapse, Institut National de la Santé et de la Recherche Médicale U497, Ecole \\ Normale Supérieure, 75005 Paris, France
}

\begin{abstract}
Disturbances of the serotoninergic neuromodulation in the cerebellar cortex have been involved in several types of ataxia, but the physiological action of serotonin in this structure remains poorly understood. We report that in slices of the rat cerebellar vermis, serotonin triggers the firing of an inhibitory interneuron presynaptic to Golgi cells. The Lugaro cell, a neglected interneuronal type, satisfies the expected criteria for this input, whereas basket cells, stellate cells, or Golgi cells do not. Lugaro cells are selectively excited by serotonin, and their firing behavior (sustained steady frequency in the 5-15 Hz range) resembles the pattern of occurrence of serotonin-evoked IPSCs in Golgi cells. Immunohistochemical stainings and single cell reconstructions show that Lugaro cell axons form a parasagittal
\end{abstract}

plexus but also extend long transverse branches that run parallel to the parallel fibers and are partly myelinated. Electrophysiological data suggest that these transverse axons participate in synaptic contacts of the Lugaro cells with Golgi cells, and we calculated that in the intact cerebellum a given Lugaro cell contacts $>100$ Golgi cells. Serotonin modulation of Lugaro cells may constitute an intracortical switch involved in information patterning at the level of Golgi cells and granule cells populations, and particularly in synchronizations recorded along the transverse axis in vivo.

Key words: serotonin; cerebellar cortex; inhibition; interneurons; Golgi cell; Lugaro cell; myelinated axons
Reciprocal interactions between the motor system and the serotoninergic modulatory system are well documented (Jacobs and Fornal, 1997). The cerebellar cortex, like all other motor structures, receives serotoninergic innervation in the form of a plexus of fine varicose fibers that do not face any differentiated postsynaptic element (Ungerstedt, 1971; Chan-Palay, 1975; Bishop and Ho, 1985; Trouillas and Fuxe, 1993). Serotonin is therefore acting in this structure as a paracrine agent, released through volume transmission. In vivo, local iontophoretic applications of serotonin have been shown to modify the spontaneous activity of the Purkinje cells, suggesting that serotonin is able to alter the input-output function of the cortex (Strahlendorf et al., 1988; Darrow et al., 1990; Kerr and Bishop, 1992). However, the molecular and cellular mechanisms responsible for this effect are still poorly understood.

It has been reported that application of serotonin potentiates the inhibition of Purkinje cells by exogenous GABA (Strahlendorf et al., 1989, 1991; Kerr and Bishop, 1992) and inhibits their excitation by exogenous non-NMDA glutamatergic ago-

Received Aug. 18, 1999; revised Dec. 23, 1999; accepted Dec. 23, 1999.

S.D. was supported by a fellowship from the Fondation Lilly, BIOMEDII BMH4CT 972374, the Ecole Normale Supérieure, and the Centre National de la Recherche Scientifique (UMR 8544). A.D. was supported by BIOMEDII BMH4CT 972374 and the Institut National de la Santé et de la Recherche Médicale (U497). We thank P. Ascher, B. Barbour, H. Gerschenfeld, S. Supplisson, and A. Triller for critical reading of this manuscript.

Correspondence should be addressed to Stéphane Dieudonné, Laboratoire de Neurobiologie, Ecole Normale Supérieure, 46 rue d’Ulm, 75005 Paris, France. E-mail: sdieudon@sfu.ca.

Copyright (C) 2000 Society for Neuroscience $0270-6474 / 00 / 201837-12 \$ 15.00 / 0$ nists in vivo (Hicks et al., 1989; Kerr and Bishop, 1992; Netzeband et al., 1993) (for review, see Bishop and Kerr, 1992). Serotonin also modulates the potassium conductance activated by depolarization $\left(I_{\mathrm{A}}\right)$ (Wang et al., 1992) as well as the cationic conductance activated by hyperpolarization $\left(I_{\mathrm{h}}\right)(\mathrm{Li}$ et al., 1993) recorded from Purkinje cells in cerebellar slices. Finally, serotonin may affect the efficiency of excitatory transmission at mossy fiber terminals (Maura et al., 1991; Lu and Larson-Prior, 1996) and parallel fiber synapses in the molecular layer (Raiteri et al., 1986; Maura and Raiteri, 1996).

In this work we have combined electrophysiological recordings in thin slices of the rat cerebellar cortex with cell reconstruction and immunohistochemical methods to identify a new site of action of serotonin. Recordings from Golgi cells revealed that serotonin $(1 \mu \mathrm{M})$ evokes numerous IPSCs, whose pattern of occurrence reveals the regular spiking of a small number of inhibitory interneurons presynaptic to Golgi cells. We show that the Lugaro cells, whose connectivity and function have remained poorly known since their initial description (Lugaro, 1894), have the properties expected from such interneurons. They are selectively excited by serotonin, in contrast to stellate cells, basket cells, and Golgi cells. Immunohistochemical and electrophysiological data suggest that Lugaro cells contact Golgi cells through longitudinal axons, which have the orientation and extension of parallel fibers. We propose that Lugaro cells, by providing synchronous inhibition to many Golgi cells, will affect the pattern of inhibitory input from Golgi cells to large populations of granule cells. Lugaro cells may therefore constitute a cellular substrate for serotonin-controlled information processing in the cerebellar cortex, accounting for the role of serotonin in several types of cerebellar ataxia (Trouillas and Fuxe, 1993). 


\section{MATERIALS AND METHODS}

\section{Slice preparation}

Cerebellar thin slices were prepared from male Wistar rats aged from 11 to $21 \mathrm{~d}$, following the method originally described by Llinás and Sugimori (1980) with slight modifications (Llano et al., 1991). Rats were decapitated, and the cerebellum was rapidly dissected and immediately cooled to $0^{\circ} \mathrm{C}$. A parasagittal cut was made in the paravermis, and parasagittal slices (180- to $250-\mu \mathrm{m}$-thick) were cut from the vermis with a microslicer (Dosaka, Kyoto, Japan, or Leica, Nussloch, Germany). They were kept at $34^{\circ} \mathrm{C}$ for $1-9 \mathrm{hr}$ before being transferred to the recording chamber. On some occasions slices were allowed to cool slowly from $34^{\circ} \mathrm{C}$ to room temperature $1 \mathrm{hr}$ after slicing.

Slices were visualized using a $40 \times$ water-immersion objective $(0.75$ NA, Axioskop, Carl Zeiss) and near-infrared optics (illumination filter $750 \pm 30 \mathrm{~nm}$, and a Sony CCD camera from which the infrared blocking filter had been removed). Golgi cells were selected for recording both on visual criteria, as previously explained (Dieudonné, 1995), and on the basis of their characteristic passive electrical properties (Dieudonné, 1998). Purkinje cells were visually identified. Putative Lugaro cells were visually selected by their position next to the Purkinje cell bodies and by the bipolar shape of their soma and proximal dendrites. Although Golgi cells located near the Purkinje cell layer can be mistaken for Lugaro cells, most Golgi cells could be discarded on the basis of their large axonal capacitive transient (Dieudonné, 1998). In all cases the recorded cells were filled with biocytin for later observation of their morphology. We found that some of the putative Lugaro cells had been mistyped and had the somatodendritic morphology of Golgi cells: basolateral dendrites radiating from the cell body and apical dendrites ascending vertically into the molecular layer. The Golgi cells with cut axons were discarded. Recordings were restricted to Purkinje, Lugaro, and Golgi cells of lobules I-V III of the vermis. Lobules IX and X, which belong functionally to the vestibulocerebellum, were discarded from this study to limit the variability associated with the specialization of the different regions of the cerebellar cortex.

Patch-clamp recording. All experiments were performed at room temperature $\left(20-25^{\circ} \mathrm{C}\right)$. The recording chamber was continuously perfused at a rate of $1.5 \mathrm{ml} / \mathrm{min}$ with a saline solution, $\mathrm{pH} 7.4$, containing (in $\mathrm{mM}$ ): $125 \mathrm{NaCl}, 2.5 \mathrm{KCl}, 2 \mathrm{CaCl}_{2}, 1 \mathrm{MgCl}_{2}, 1.25 \mathrm{NaH}_{2} \mathrm{PO}_{4}, 26 \mathrm{NaHCO}_{3}$, and 25 glucose, bubbled with a mix of $95 \% \mathrm{O}_{2}$ and $5 \% \mathrm{CO}_{2}$. The same solution was used during dissection and slicing. TTX (Sigma, St. Louis, MO), APV (Tocris), CNQX (Tocris), and gabazine (RBI) were bathapplied. Serotonin (Sigma) was also bath-applied, usually for $3 \mathrm{~min}$, and washed for at least $15 \mathrm{~min}$ between applications to avoid desensitization.

Golgi cells were recorded in cell-attached and whole-cell configurations. In both cases the voltage-clamp mode was used with the pipette potential held at $-70 \mathrm{mV}$. Pipettes had a resistance of 2-4 M $\Omega$ and were filled with the following internal solution (in mM): $142 \mathrm{CsCl}, 10 \mathrm{HEPES}$, 1 EGTA, $5 \mathrm{MgCl}_{2}, 0.1 \mathrm{CaCl}_{2}$, $4 \mathrm{Na}$-ATP, $0.4 \mathrm{Na}-\mathrm{GTP}$; $\mathrm{pH}$ adjusted to 7.3 with $N$-methyl-D-glucamine. Purkinje cells were recorded in the whole-cell configuration with the solution described above and held at $-70 \mathrm{mV}$. Lugaro cells were recorded in the voltage-clamp mode in the cell-attached configuration and at the beginning of the whole-cell configuration. After compensation of the pipette capacitance, access resistance, and whole-cell capacitance, the amplifier (Axopatch 200B, Axon Instruments) was switched to the current-clamp mode. Pipettes had a resistance of 4-6 $\mathrm{M} \Omega$ and were filled with the following internal solution (in mM): $140 \mathrm{~K}$-gluconate, $6 \mathrm{KCl}, 10 \mathrm{HEPES}, 1 \mathrm{EGTA}, 0.1 \mathrm{CaCl}_{2}, 5$ $\mathrm{MgCl}_{2}, 4 \mathrm{Na}-\mathrm{ATP}, 0.4 \mathrm{Na}-\mathrm{GTP}$; $\mathrm{pH}$ adjusted to 7.3 with $\mathrm{KOH}$. All recordings were stored on a D.A.T. recorder (DTR-1204, BioLogic) and digitized off-line.

Data analysis. PClamp software (Axon Instruments) was used for the acquisition of all recordings. Data were filtered at $2 \mathrm{kHz}$ and digitized at $10 \mathrm{kHz}$. Spontaneous synaptic currents were detected automatically using the ACS software kindly provided by P. Vincent (Institut des Neurosciences, Paris). All detected events were subjected to visual inspection, and EPSCs were discarded on the basis of their fast decay time course (Dieudonné, 1998). Selected events could then be transferred in a file with the format of clampex files and further analyzed using the Clampfit program of the PClamp6 package.

Morphological reconstruction. For Lugaro cell recordings, biocytin $(2-5 \mathrm{mg} / \mathrm{ml})$ was added to the intracellular solution just before the experiment. At the end of whole-cell recordings, the patch pipette was slowly moved away from the cell to obtain an outside-out patch. The slice was then fixed at $4^{\circ} \mathrm{C}$ in PBS $(150 \mathrm{~mm})$ containing $4 \% \mathrm{w} / \mathrm{w}$ paraformaldehyde (PFA) and sometimes $0.05 \% \mathrm{v} / \mathrm{v}$ glutaraldehyde. After $12 \mathrm{hr}$ to 2 weeks of fixation, biocytin was revealed using the $\mathrm{ABC}$ elite kit (Vector Laboratories, Burlingame, CA). Slices were preincubated for $10 \mathrm{~min}$ in $10 \%$ methanol, $89 \%$ PBS, and $1 \% \mathrm{H}_{2} \mathrm{O}_{2}$ to remove endogenous peroxidase activity. They were then permeabilized for 30 min with $0.4 \%$ Triton $\mathrm{X}-100$ in PBS and incubated for $2 \mathrm{hr}$ with the avidin derivatives. Peroxidase activity was revealed by incubation in a Tris solution containing $0.015 \%$ diaminobenzidine, $0.15 \%$ nickel ammonium sulfate, and 0.4 $\mu \mathrm{l} / \mathrm{ml}$ of a $1 \% \mathrm{H}_{2} \mathrm{O}_{2}$ solution, after a preincubation for $20 \mathrm{~min}$ in a similar solution without $\mathrm{H}_{2} \mathrm{O}_{2}$. Alternatively, biocytin was revealed with FITCcoupled streptavidin (1:200, Transduction Laboratories) for $2 \mathrm{hr}$. In this case, fixation was performed at $4^{\circ} \mathrm{C}$ with $4 \%$ w/w PFA in PBS for $3-12 \mathrm{hr}$. The reconstructed image of a Lugaro cell presented in this paper was drawn from serial images taken every $1 \mu \mathrm{m}$ with a Hamamatsu CCD camera (C5985) mounted on a standard epifluorescence microscope (Leica DMRD).

Fluorescence immunohistochemistry. Female Sprague Dawley rats (180-200 gm, Janvier) were deeply anesthetized with pentobarbital (60 $\mathrm{mg} / \mathrm{kg}$ body weight, i.p.) and perfused intracardially with $4 \% \mathrm{w} / \mathrm{w}$ PFA in PBS. The cerebellum was removed, post-fixed for $12-15 \mathrm{hr}$ in the same fixative, and cut into $30-\mu \mathrm{m}$-thick sections with a vibratome in sagittal or transverse planes. Sections were immersed for $20 \mathrm{~min}$ in $50 \mathrm{~mm}$ ammonium chloride in PBS and rinsed. After $30 \mathrm{~min}$ of preincubation in $0.1 \%$ gelatin, $0.1 \%$ Triton $\mathrm{X}-100$ in PBS, an overnight incubation at $4^{\circ} \mathrm{C}$ was performed in the same solution either with a polyclonal anti-calretinin antibody alone (1:5000, SWant) or combined with (1) a monoclonal anti-GAD65 antibody (1:500, Boehringer Mannheim, Indianapolis, IN) (Gottlieb et al., 1986) or (2) a monoclonal anti-myelin basic protein (anti-MBP) antibody (1:100, Chemicon, Temecula, CA) (Groome et al., 1986). After they were rinsed, sections were incubated for $2 \mathrm{hr}$ with a biotin-coupled goat anti-rabbit IgG (1:200, Jackson ImmunoResearch Laboratories), revealed by using FITC-coupled streptavidin (1:200, Jackson ImmunoResearch Laboratories). If necessary, these antibodies were combined with a CY3-coupled goat anti-mouse IgG (1:500, Jackson ImmunoResearch Laboratories). Sections were mounted with Vectashield (Vector Laboratories) before examination with a standard epifluorescence microscope (Leica DMRD). No staining was observed when primary antibodies were omitted.

\section{RESULTS}

\section{Inhibition of Golgi cells is under serotoninergic control}

Figure $1 A, B$ illustrates the effect of serotonin $(1 \mu \mathrm{M})$ on the synaptic activity recorded from Golgi cells. Before application of serotonin, synaptic currents occurred at low frequency and at random intervals, as illustrated in Figure $1 B$. After bath application of serotonin, the synaptic activity dramatically increased. In Figure $1 B$ the fast synaptic currents are EPSCs, which can be blocked by AMPA receptor antagonists (Dieudonné, 1998), whereas the synaptic currents with a slower decay are IPSCs, which can be blocked by the combined application of gabazine and strychnine (Dieudonné, 1995). As can be seen in Figure $1 B$, serotonin induced a dramatic increase in the frequency of the IPSCs but not the EPSCs. In eight cells recorded under the same conditions as the cell in Figure 1, the IPSC frequency raised from a basal level of $2.7 \pm 0.9 \mathrm{~Hz}$ to a peak of $13 \pm 8 \mathrm{~Hz}$ [mean $\pm \mathrm{SD}$; minimum $(\min )=1.5 \mathrm{~Hz}$; maximum $(\max )=25 \mathrm{~Hz}]$. Serotonin increased the frequency of the IPSCs in 36 of 51 Golgi cells. The fraction of the cells in which serotonin did not evoke IPSCs dropped from 0.32 at postnatal day (P) $11-14(n=37)$ to 0.14 at P16-25 $(n=14)$.

For the cell of Figure 1, the amplitude histograms of the IPSCs in control conditions and during serotonin application are displayed in $C$. In this cell control IPSCs had a mean amplitude of $32 \mathrm{pA}$ (average amplitude: $33 \pm 10 \mathrm{pA} ; n=8$ Golgi cells), and the amplitude of the serotonin-induced IPSCs was 10.7 times that of the spontaneous IPSCs recorded in control conditions. Therefore Golgi cells receive two classes of IPSCs that can be separated by their frequency of occurrence before and during serotonin application and by their amplitude (Fig. $1 C$ ). On average, the ratio of 


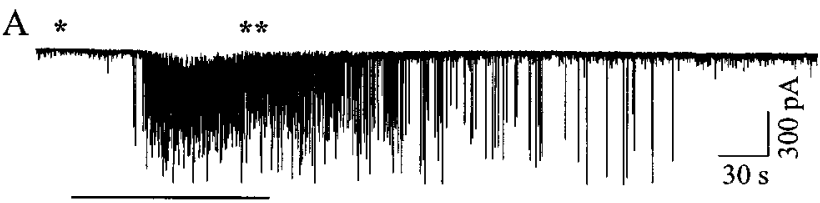

5-HT
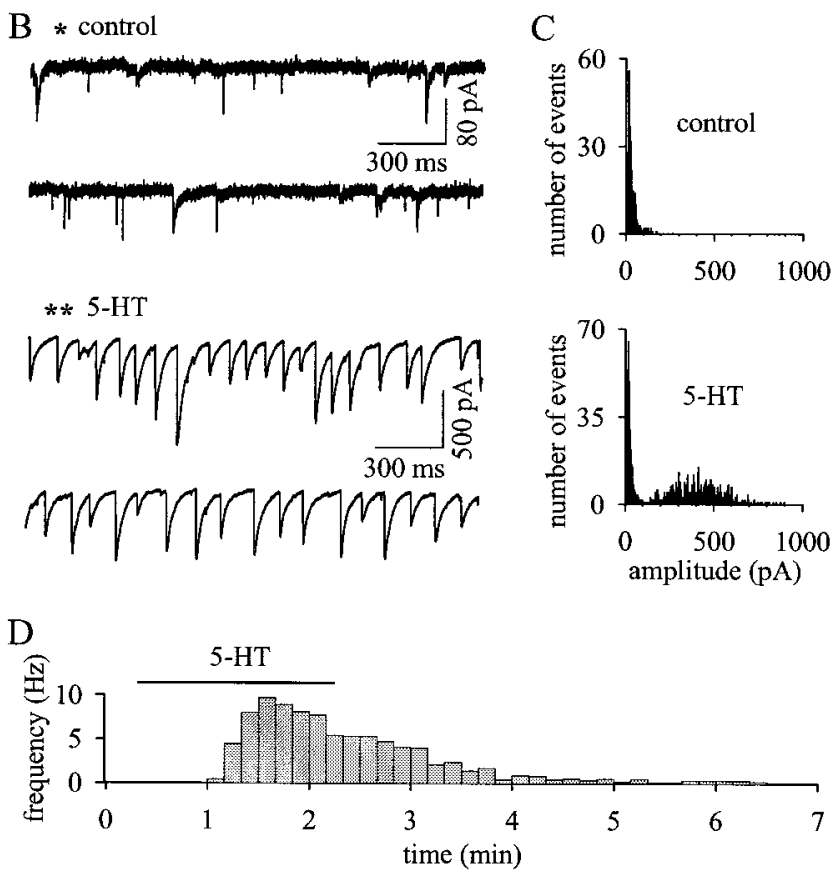

Figure 1. Serotonin increases the inhibitory synaptic activity recorded from cerebellar Golgi cells. The spontaneous synaptic activity was recorded from a Golgi cell held at $-70 \mathrm{mV}$ in the whole-cell configuration of the patch-clamp technique. $A$, Continuous recording (448 sec) is displayed to show the effect of bath application of $1 \mu \mathrm{M}$ serotonin on the spontaneous synaptic activity. B, Representative recordings, at a faster time scale, in control conditions and in the presence of serotonin were taken from the trace in $A$ at the time indicated by asterisks. In control conditions fast EPSCs and slowly decaying IPSCs occur at low frequency. In the presence of serotonin the activity is dominated by large IPSCs occurring at high frequency. $C$, Amplitude histogram of the IPSCs in control conditions and in the presence of serotonin. The detection threshold was set at $-10 \mathrm{pA}$, and events were grouped in $5 \mathrm{pA}$ bins. The range of amplitudes of serotonin-induced IPSCs is completely distinct from that of control IPSCs. $D$, Average frequency of occurrence of IPSCs $>200 \mathrm{pA}$ over $10 \mathrm{sec}$ bins (same recording as in $A$ ).

the amplitude of serotonin-evoked IPSCs over that of control IPSCs was $4.0 \pm 1$ (mean $\pm \mathrm{SEM} ; n=13$; $\min =0.4$; $\max =12)$. In some Golgi cells the amplitude of the serotonin-evoked IPSCs decreased markedly during the application of serotonin (Fig. 2A). This rundown might have to do with the state of preservation of the presynaptic cell, which in the case of Figure $2 A$ seemed to display a low level of spontaneous activity before serotonin application (as assessed from the presence of a population of large amplitude IPSCs in control conditions).

The time course of the effect of serotonin is better illustrated by the frequency of occurrence of the serotonin-evoked IPSCs (separated from control IPSCs by their amplitudes) shown in Figure $1 D$. The first IPSCs appeared after a delay of $\sim 30 \mathrm{sec}$ after the arrival of serotonin in the bath. This value is calculated by substraction of the bath perfusion delay, which has been assessed from the time course of IPSC inhibition when applying the

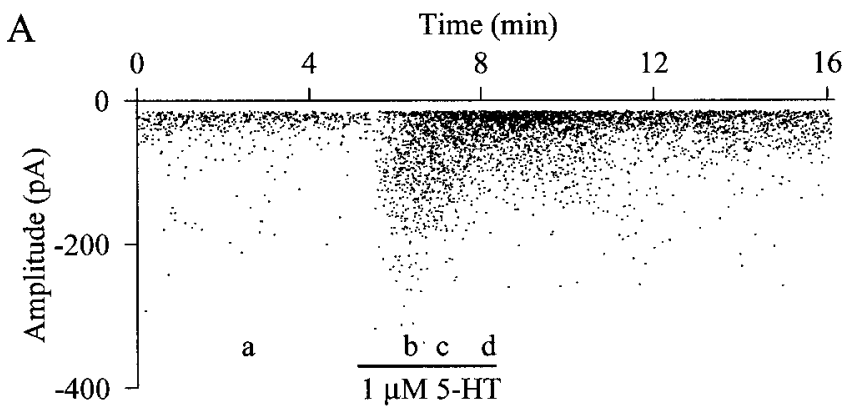

$\mathrm{B}$ a
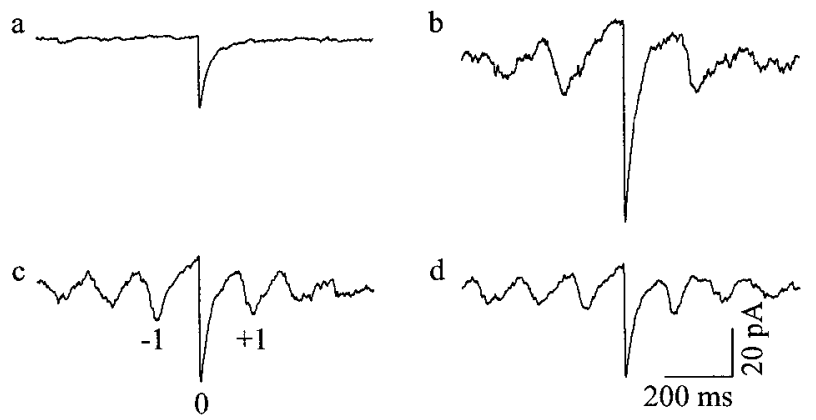

C

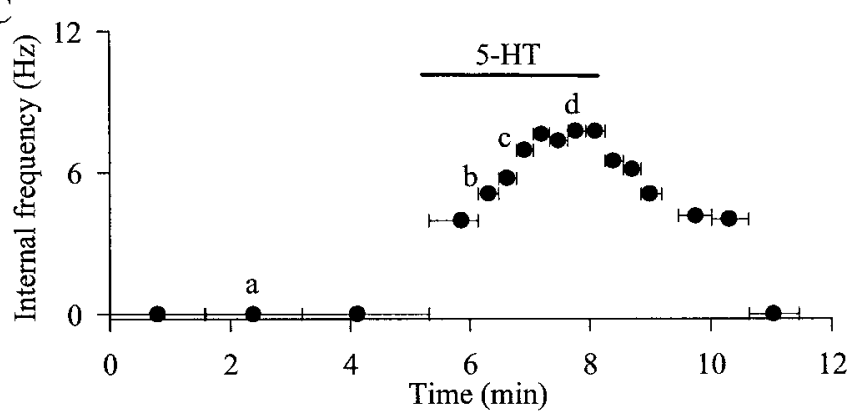

Figure 2. Analysis of the rhythm of the inhibitory IPSCs evoked by serotonin. $A$, Dot plot of the effect of serotonin on the inhibitory activity recorded from a Golgi cell. Each dot indicates the amplitude and time of occurrence of an IPSC. Note that events with an amplitude similar to the serotonin-induced events are recorded before serotonin application, indicating that in that case the serotonin-sensitive presynaptic interneuron was firing at low frequency in control conditions. A large decrease in the amplitude of the serotonin-induced IPSCs is observed during the effect. $B, a$, IPSCs recorded during the control period $a$ illustrated in $A$ were aligned on the first point of their rising phase and then averaged. The same operation was performed on groups of 200 consecutive IPSCs taken during the onset $(b)$, the peak $(c)$, and the steady-state $(d)$ of the effect of serotonin. The regularly spaced wavelets in the three averages indicate that during the action of serotonin there is a strong level of autocorrelation in the responses. The number 0 indicates the peak corresponding to the averaged event; -1 and +1 mark the peaks corresponding to the previous and next events. The interval $(I)$ between peaks -1 and +1 was used to calculate the internal frequency $(f)$ of the IPSC rhythm $(f=2 / I)$. Note that the increase in frequency from $b$ to $c$ is correlated to a decrease in the amplitude of the serotonin-evoked IPSCs. $C$, Plot of the internal frequency versus time. The first three points and the last point correspond to control period and recovery, when no significant rhythm could be observed. Each point is placed at the mean value of the time of occurrence of the averaged IPSCs, and horizontal bars indicate the beginning and the end of the periods taken for average.

$\mathrm{GABA}_{\mathrm{A}}$ antagonist gabazine. This delay for the appearance of serotonin-evoked IPSCs varied largely between cells, from a few seconds to $>3 \mathrm{~min}$. The effect of serotonin was entirely reversible within 5-10 min (Fig. 1A,D). The serotonin-induced increase in IPSC frequency could be repeated many times on the same cell, 
although in several cells a decrease in the peak frequency that was reached could be noted between the first and subsequent applications.

In all of the Golgi cells recorded before P12, serotonin decreased the amplitude and frequency of the spontaneous IPSC. This inhibitory effect was better seen in cells in which serotonin did not evoke a new class of IPSCs. Both effects could also superimpose, in which case the inhibitory effect, having a negligible latency, would precede the appearance of the serotoninevoked IPSCs. The inhibitory effect was never recorded in cells after P15 and will not be discussed further.

\section{Serotonin induces spike firing of inhibitory interneurons presynaptic to the Golgi cell}

The large-amplitude IPSCs induced by serotonin may result from an increase in the release probability at previously active synapses or from the excitation of previously silent interneurons. The fact that serotonin induces a gradual increase in the frequency of the IPSCs but a sharp increase in their amplitude (Figs. 1-3) argues for the second hypothesis. Bath-applied TTX $(0.2-1 \mu \mathrm{M})$ blocked completely and reversibly the increase in IPSC frequency induced by serotonin ( $n=3$; data not shown), which indicates that the release probability for miniature events is not affected. Moreover, the effect of serotonin was unaffected by coapplication of CNQX $(5 \mu \mathrm{M})$ and DL-APV $(50 \mu \mathrm{M})(n=3$; data not shown), indicating that it does not depend on the activity of glutamatergic synapses. Taken together, these data suggest that serotonin directly induces spike firing in a population of presynaptic interneurons that are silent in control conditions but does not increase the release probability at previously active synapses.

\section{Serotonin transforms silent interneurons into regularly firing ones}

The pattern of activity of the serotonin-driven inhibitory afferents to Golgi cells was found to be highly rhythmic. The regular occurrence of serotonin-induced IPSCs can be visually appreciated (Fig. $1 B$ ), but to better characterize this rhythm, IPSCs were aligned on the first point of their rising phase and averaged both in control conditions and during serotonin applications. The dot plot in Figure $2 A$, which indicates the time of occurrence and amplitude of all IPSCs, illustrates a representative experiment in which, after a delay of $\sim 30 \mathrm{sec}$, the IPSC frequency rose during $\sim 90 \mathrm{sec}$ (period indicated by $b$ ) and then settled to a steady-state (periods indicated by $c$ and $d$ ). The frequency returned close to control values within $8 \mathrm{~min}$ of washout of serotonin. In control conditions the average IPSC rises rapidly from a flat baseline and decays monotonically (Fig. $2 B, a$ ). In contrast, the averaged trace obtained during serotonin application (Fig. $2 B, b, c, d$ ) was composed of a series of wavelets with equidistant peaks on both sides of the averaged IPSC (marked 0 on Fig. $2 B, c$ ). The shape of this crude autocorrelogram means that in the presence of serotonin, IPSCs occur with an extreme regularity. The main frequency can be calculated as the inverse of the interval between peaks. As shown in Figure $2 C$, the rhythm appeared at the onset of the effect. The firing frequency of the presynaptic interneuron rose gradually (from 4.1 to $7.9 \mathrm{~Hz}$ ) during the first minute of serotonin application to reach a steady-state rate that did not decrease with time. The rhythmic activity also persisted during most of the offset, decreasing gradually to half of the maximum frequency $(4.1 \mathrm{~Hz})$, until rare random events were left. The stability and regularity of the periodic occurrence of IPSCs indicate that serotonin-sensitive interneurons behave, in the presence of sero-

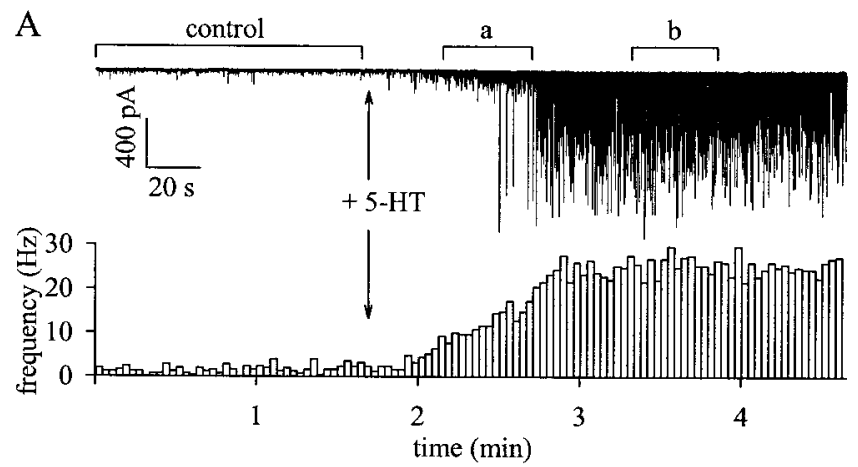

B Amplitude distributions

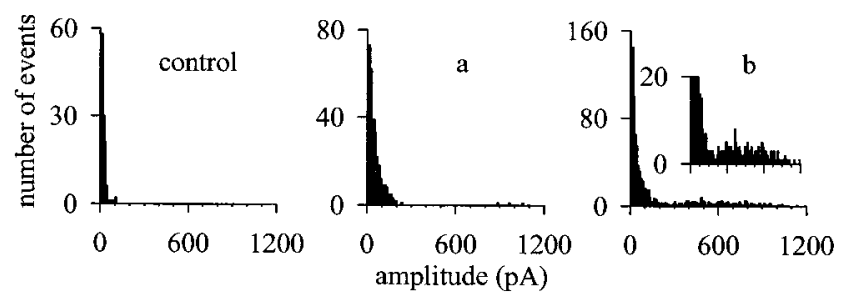

C Rhythms during period $\mathrm{b}$

$70 \mathrm{pA}<\mathrm{ipsc}<200 \mathrm{pA} \quad 200 \mathrm{pA}<\mathrm{ipsc} \quad 70 \mathrm{pA}<\mathrm{ipsc}$

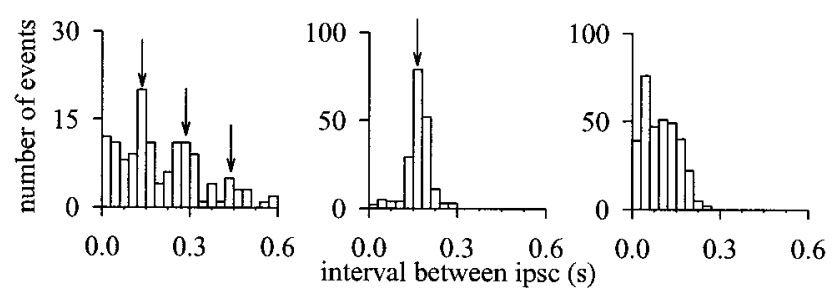

Figure 3. Several serotonin-sensitive interneurons can be presynaptic to the same Golgi cell. A, A $280 \mathrm{sec}$ whole-cell recording shows the beginning of the effect of serotonin $(1 \mu \mathrm{M})$. The bar chart represents the mean IPSC frequency during $2.5 \mathrm{sec}$ intervals for the same period of recording. The brackets on top of the trace indicate the periods used for the analysis in $B$ and $C$. $B$, Amplitude histogram of the IPSCs before serotonin application (control), at the beginning of the effect $(a)$, and after the onset of large-amplitude events $(b)$. The inset in $b$ shows the repartition of the large amplitude IPSCs at a different vertical scale. The bin value is $10 \mathrm{pA}$, and the detection threshold was $-10 \mathrm{pA}$. $C$, Interval between IPSCs during period $\mathrm{b}$. IPSCs $<70 \mathrm{pA}$ were discarded to avoid contamination of the analysis by IPSCs independent from serotonin. The intervals between successive IPSCs was then calculated (right histogram). The IPSCs were further divided into two classes of amplitudes (70-200 pA and $>200 \mathrm{pA}$ ) to allow separation of small IPSCs appearing at the beginning of the effect from larger ones appearing with a longer latency. The distributions of intervals between successive IPSCs in these two classes are plotted in the left and middle histograms. The left histogram shows peaks at 140, 280, and $420 \mathrm{msec}$, whereas the histogram for large IPSCs shows a single peak around $170 \mathrm{msec}$ (arrows). Intervals are grouped in $30 \mathrm{msec}$ bins.

tonin, as oscillators with a preferred frequency. It also suggests that either a single interneuron or synchronized interneurons are responsible for the effect of serotonin in the cell of Figure 2.

\section{Several presynaptic interneurons can be recruited by serotonin with different latencies}

In some Golgi cells the onset of the effect of serotonin was clearly multiphasic. As illustrated in Figure $3 A$, multiple phases can be distinguished relative to both the amplitude and frequency of the serotonin-evoked IPSCs. As illustrated in the left plot of Figure $3 B$, control IPSCs recorded in this experiment had an amplitude 
$<70$ pA. During the first phase of the effect, the serotonininduced IPSCs had a larger amplitude than control IPSCs but remained $<200 \mathrm{pA}$ (Fig. $3 B$, middle plot). While the frequency of this intermediate class of events still rose, IPSCs $>200$ pA began to occur with increasing frequency. The successive classes of events did not replace the smaller ones (Fig. $3 B$, right plot), as would have been the case with an increase in the strength of a single presynaptic unit.

Multiple peaks were observed in the average IPSC calculated (as in Fig. 2) for the initial period a, indicating a preferred firing frequency of $6.4 \mathrm{~Hz}$ for the presynaptic units (data not shown). In contrast, multiple peaks did not appear if the average was performed later (Fig. 3, period $b$ ). To further analyze period $b$, IPSCs were separated into two groups according to their amplitudes: 70-200 pA, corresponding to the amplitude of the initial IPSCs induced by serotonin, and over $>\mathrm{pA}$, corresponding to the amplitude of the IPSCs induced later. The distributions of the intervals between successive events, calculated for each population individually, are plotted in Figure $3 C$. Intervals were distributed in equidistant peaks. The preferred intervals were multiples of $145 \mathrm{msec}(6.9 \mathrm{~Hz}$, small IPSCs) and $170 \mathrm{msec}(5.9 \mathrm{~Hz}$, large IPSCs), respectively. In contrast, when the IPSCs belonging to the two classes of amplitude were considered together (amplitude $>70$ pA) (Fig. 3C, right plot) intervals between 0 and $200 \mathrm{msec}$ were found to be equally likely, and longer intervals never occurred. Therefore the two classes of amplitudes correspond to IPSCs coming from two distinct presynaptic units that fire regularly at similar frequencies but independently from each other. In two other cells, in which the IPSCs during the successive phases of the effect of serotonin had very different amplitudes, a similar analysis gave the same results: preferred intervals for each amplitude population alone but short random intervals for the overall population. This confirms that the multiphasic effects of serotonin indicate the sequential excitation of several independent presynaptic interneurons.

\section{Serotonin does not increase the activity of molecular layer interneurons or of Golgi cells}

We sought to identify the serotonin-sensitive interneuron presynaptic to Golgi cells. Early studies have shown that Golgi cells are contacted by basket cells and stellate cells (Eccles et al., 1967; Palay and Chan-Palay, 1974). To test whether these molecular layer interneurons are sensitive to serotonin, we examined the effect of serotonin on the inhibitory synaptic activity recorded from Purkinje cells, their main postsynaptic target, in conditions in which the EPSCs were blocked by $5 \mu \mathrm{M}$ CNQX. The effect of bath application of serotonin is illustrated in Figure $4 A$ and quantified in $B$ and $C$. Serotonin slightly reduced the amplitude and the frequency of the IPSCs. The frequency decrease was more progressive and had a longer latency than the amplitude decrease. The mean amplitude and frequency measured after 6 min of application were 68 and $72 \%$, respectively, of control values. Although interinhibition between molecular layer interneurons may have reduced the amplitude of the frequency increase induced by serotonin, it is unlikely to have transformed it into a frequency decrease. The results therefore indicate that serotonin is unable to excite basket and stellate cells.

The effect of serotonin does not involve Purkinje cell to Golgi cell connections. Some authors have proposed that the recurrent collaterals of Purkinje cell axons contact Golgi cells (Ramón y Cajal, 1911; Palay and Chan-Palay, 1974). However, a more systematic survey has shown that these axons synapse primarily
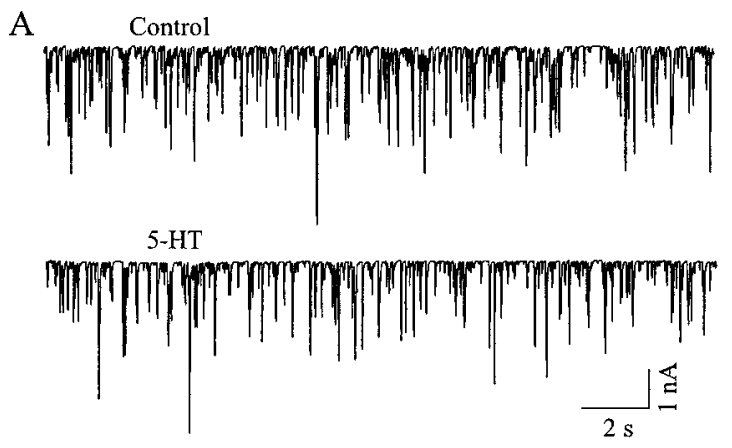

$\mathrm{B}$
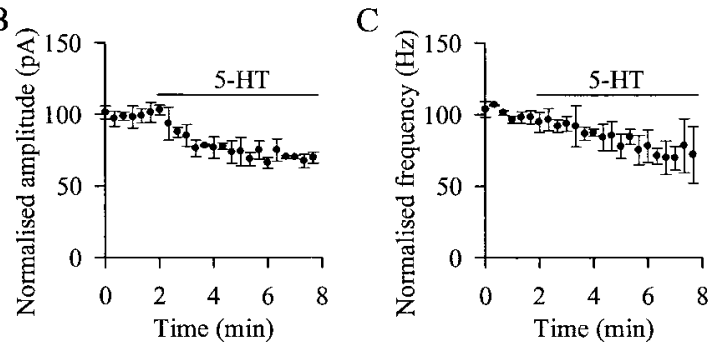

Figure 4. Serotonin decreases the inhibitory synaptic activity recorded from Purkinje cells. Purkinje cells were held at $-60 \mathrm{mV}$ and recorded in the presence of $5 \mu \mathrm{M} \mathrm{CNQX}$ to block the EPSCs. A, Spontaneous inhibitory activity recorded before and after addition of serotonin $(1 \mu \mathrm{M})$ to the bath. $B, C$, Mean amplitudes and mean frequencies were calculated over $20 \mathrm{sec}$ intervals for three Purkinje cells. In each cell they were normalized to the mean amplitude and the mean frequency during the whole control period. The normalized values were then aligned at the onset of the serotonin application and averaged to give the plots in $B$ and $C$. Error bars indicate the SEM.

just under the Purkinje cells with so-called "low basket cells" (Larramendi and Lemkey-Johnston, 1970), which can be identified as Lugaro cells and not as Golgi cells. The pericellular baskets described by Ramón y Cajal (1911) around interneurons deep in the granular layer probably correspond to contacts with ectopic Lugaro cells, which are abundant in the cat (Sahin and Hockfield, 1990). If Purkinje cells were presynaptic to Golgi cells, they should produce an intense background inhibitory activity, because most Purkinje cells are spontaneously firing in the slice. As shown in Figures 1-3, the background inhibition is low. Purkinje cell activity is therefore not likely to account for the serotonin-driven inhibition recorded from Golgi cells.

The serotonin effect does not involve Golgi-Golgi interactions. This was made unlikely by the fact that connections between Golgi cells have never been described in morphological studies and by our previous observation (Dieudonné, 1998) that most Golgi cells are spontaneously active in slices, unlike the serotonin-sensitive presynaptic neuron. To further exclude this possibility, we recorded the spontaneous firing of Golgi cells in the cell-attached mode $(n=11)$. The frequency of the spikes was not significantly affected by bath-application of serotonin, except in one cell for which the frequency was decreased (data not shown).

In view of the above results, it is unlikely that the serotoninsensitive inhibitory interneurons presynaptic to Golgi cells are basket cells, stellate cells, Purkinje cells, or Golgi cells.

\section{Serotonin transforms inactive Lugaro cells into regular spiking neurons}

The only other possible target of serotonin, given the classification of cerebellar cell types, was the Lugaro cell, a poorly char- 
A

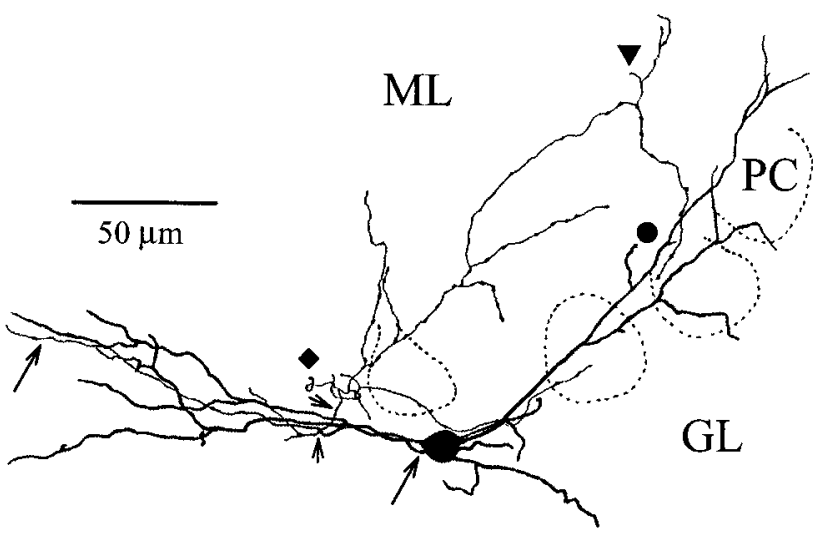

D

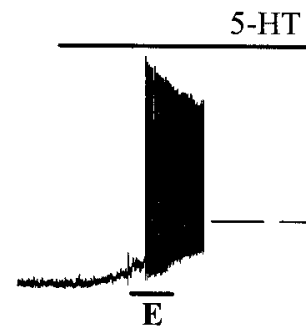

E

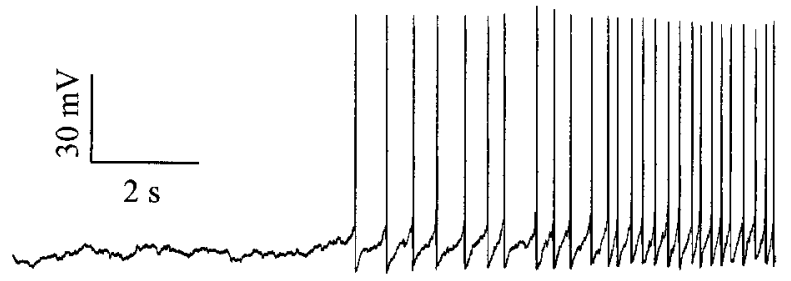

B

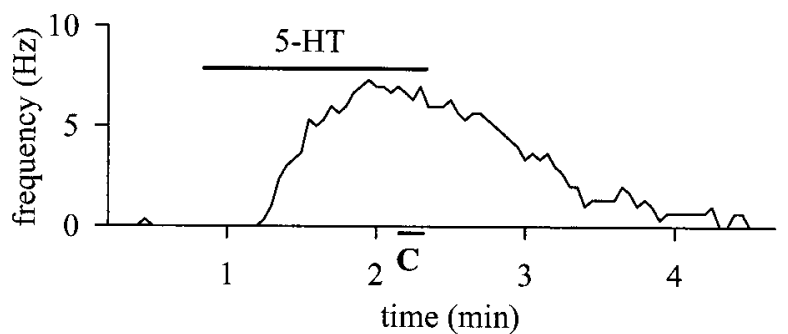

C

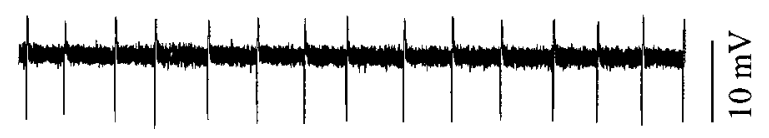

$0.5 \mathrm{~s}$

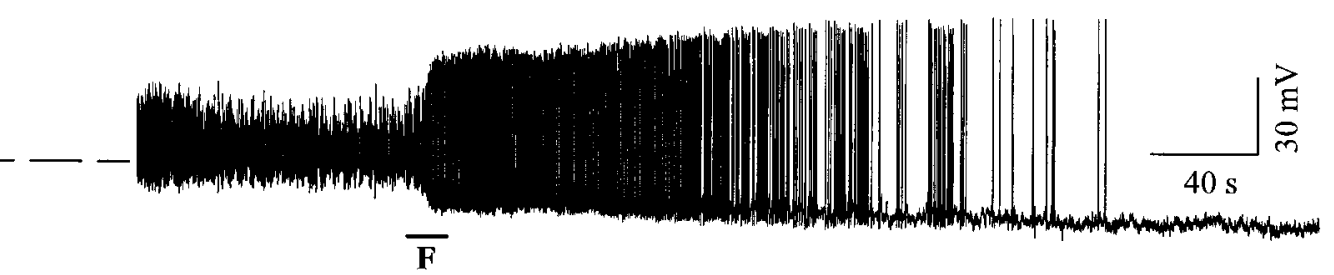

$\mathrm{F}$

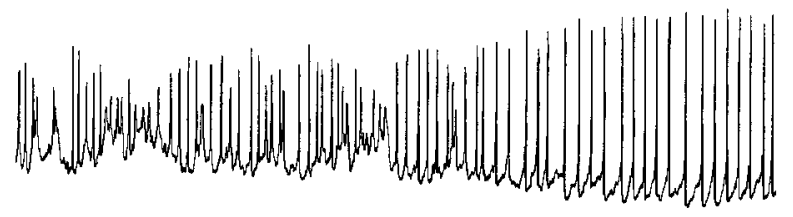

Figure 5. Serotonin excites Lugaro cells identified morphologically. $A$, Reconstruction of a biocytin-filled Lugaro cell in the parasagittal plane. The cell was located at the bottom of a lobule, and the two main dendritic trees marked the curvature of the Purkinje cell layer $(P C)$. A third dendrite, descending in the granular layer, was cut at approximately $50 \mu \mathrm{m}$ from the cell body. Thin varicose fibers formed an axonal plexus in the parasagittal plane inside the molecular and Purkinje cell layers. This plexus originated (short arrows) from a neurite running among the main dendrites. It was not possible to assess whether this neurite (arrows) was an axon or a dendrite. The indicates a transverse axonal branch emerging from the parasagittal plexus and running toward the surface where it was cut. The $\boldsymbol{\nabla}$ points to a varicose branch of the axon running toward the depth of the slice. The indicates another transverse neurite that was emitted by a main dendrite. $B$, Summary of the firing frequency of a Lugaro cell recorded in the cell-attached configuration. $C$, Part of the cell-attached recording marked in $B$. $D$, Whole-cell current-clamp recording of a Lugaro cell. The holding current was set to - 10 pA. Serotonin induced sustained, reversible firing of the Lugaro cell. Firing frequency is marked by abrupt transitions at both the onset $(E)$ and offset $(F)$, which correlate with different levels of plateau depolarizations. $E, F$, Display of the parts marked in $D$ at a faster time scale.

acterized cerebellar interneuron that was first identified by its bipolar shape and location under the Purkinje cell bodies (Lugaro, 1894). Immunohistochemical studies have confirmed that it represents a distinct cell type (Rogers, 1989; Sahin and Hockfield, 1990). Morphological studies have been devoted to this cell type recently (Lainé and Axelrad, 1996, 1998), but nothing is known about its electrophysiological properties.

Putative Lugaro cells can be identified in the slice by their shape and position. This visual identification remains ambiguous because some Golgi cells can be found in the same location (Sahin and Hockfield, 1990), and the definitive identification of Lugaro cells could only be established on the basis of morphological criteria after revelation of the biocytin injected in recorded cells (see Materials and Methods). The parasagittal reconstruction of a Lugaro cell is shown in Figure $5 A$. The dendrites of the Lugaro cells ran in or under the Purkinje cell layer for $\sim 200 \mu \mathrm{m}$ in each direction. In some cells one dendrite also descended in the granular layer to reach the white matter (in Fig. $5 A$ it is cut at $50 \mu \mathrm{m}$ from the cell body) but no dendrite was ever found to enter the molecular layer. This characteristic mor- phology (a description of the axonal plexus is given below) is correlated with the absence of spontaneous spikes in the cellattached mode $(n=8)$ in contrast with Golgi cells (Dieudonné, 1998). Lugaro cells are therefore different from Golgi cells, both morphologically and electrophysiologically.

In the cell-attached configuration, serotonin $(1 \mu \mathrm{M})$ evoked the firing of action potentials in three of three Lugaro cells, as illustrated in Figure $5 B, C$. The firing frequency was sustained in the presence of serotonin, and the spikes occurred at regular intervals (Fig. 5C). On washout of serotonin the firing gradually stopped within 2-3 min. Lugaro cells were also recorded in the whole-cell current-clamp mode. The holding current was fixed as the inverse of the leak current through the seal in the cellattached configuration just before the membrane was broken $(-10$ to $-25 \mathrm{pA})$. In these conditions application of serotonin at the beginning of the whole-cell recordings induced a depolarization of the Lugaro cells but the effect could never be repeated a second time after 15 min of recovery from the first application. This "washout" was accompanied by a spontaneous hyperpolarization of the cell, indicating that intracellular components im- 
portant for the regulation of the resting potential and for the serotonin-induced depolarization are lost gradually during intracellular dialysis. In the whole-cell current-clamp configuration, serotonin depolarization did not always lead to spike firing, probably because the effect had already partially washed out at the beginning of the recording. Indeed, reducing the hyperpolarizing holding current allowed recovery of serotonin-induced spike firing in two cells.

In both cell-attached and whole-cell modes the latency of the excitatory effect of serotonin on Lugaro cells was not significantly different from the time necessary to perfuse the bath $(\sim 60 \mathrm{sec})$, whereas the effects of serotonin on the inhibitory activity recorded from Golgi cells could take as much as 3 more minutes. When spikes were initiated (Fig. 5D), the delay between the onset of depolarization and the first spike was never longer than $20 \mathrm{sec}$ and could be as short as a few milliseconds (Fig. 6B). Firing was sustained, at 5-15 Hz, during the whole serotonin application, with abrupt changes in firing frequencies at both the onset (Fig. $5 E$ ) and offset (Fig. $5 F$ ) of the effect. These frequency changes were linked to different levels of depolarizing plateaus, as shown in Figure $5 F$. During prolonged applications of serotonin, overexcitation of the Lugaro cell eventually led to chaotic firing, with a dramatic reduction in spike amplitude (Fig. $5 D, F$ ). This might explain the gradual decrease in the amplitude of serotoninevoked IPSCs observed in some Golgi cells.

The changes in active membrane properties of the Lugaro cell, which underlie the effect of serotonin, were further investigated. In current clamp, minor reductions in the hyperpolarizing holding current (from -5 to $-2 \mathrm{pA}$ in Fig. $6 A$ ) led to spike firing. In control conditions, the firing frequency displayed a marked accommodation, linked to the increased amplitude of post-spike slow afterhyperpolarizations (AHPs) during a train (Fig. 6 $\mathrm{A}$, arrows). In the same cell, application of $1 \mu \mathrm{M}$ serotonin induced a depolarization of similar amplitude, which led to high-frequency firing without any accommodation (Fig. 6B). The lack of accommodation correlates with the absence of slow AHPs and accounts for the steady firing pattern of Lugaro cells.

The effects of hyperpolarizing and depolarizing current pulses in control conditions and in the presence of $1 \mu \mathrm{M}$ serotonin were compared. The holding current was increased during serotonin application to stop serotonin-induced firing and to bring the cell back to its initial holding potential. In control conditions, a large hyperpolarizing pulse was followed at the repolarization by a small afterdepolarization, which can be attributed to the presence of an $I_{\mathrm{h}}$ current, as evidenced by the sag seen in the membrane potential recordings during hyperpolarization (Fig. $6 C$ ). In the presence of serotonin, the amplitudes of the maximal hyperpolarization and of the sag were not markedly affected, but the small afterdepolarization was transformed into a prolonged depolarizing plateau leading to the emission of several spikes (Fig. 6C). Inhibition of potassium conductances active around the resting potential may account for this increased effect of $I_{\mathrm{h}}$ and for the depolarization induced by serotonin. However, surprisingly, an afterdepolarization was also seen after depolarizing current pulses in the presence of serotonin, but not in control conditions (Fig. 6D). This pattern resembles that observed in spinal motoneurons in the presence of serotonin, which has been linked to a nifedipine-sensitive calcium current (Hounsgaard et al., 1988; Hounsgaard and Kiehn, 1989). The actual mechanism generating depolarizing plateau in Lugaro cells may thus involve a modulation of both potassium and calcium currents, or may even be more complicated, as for the calcium-dependent after-
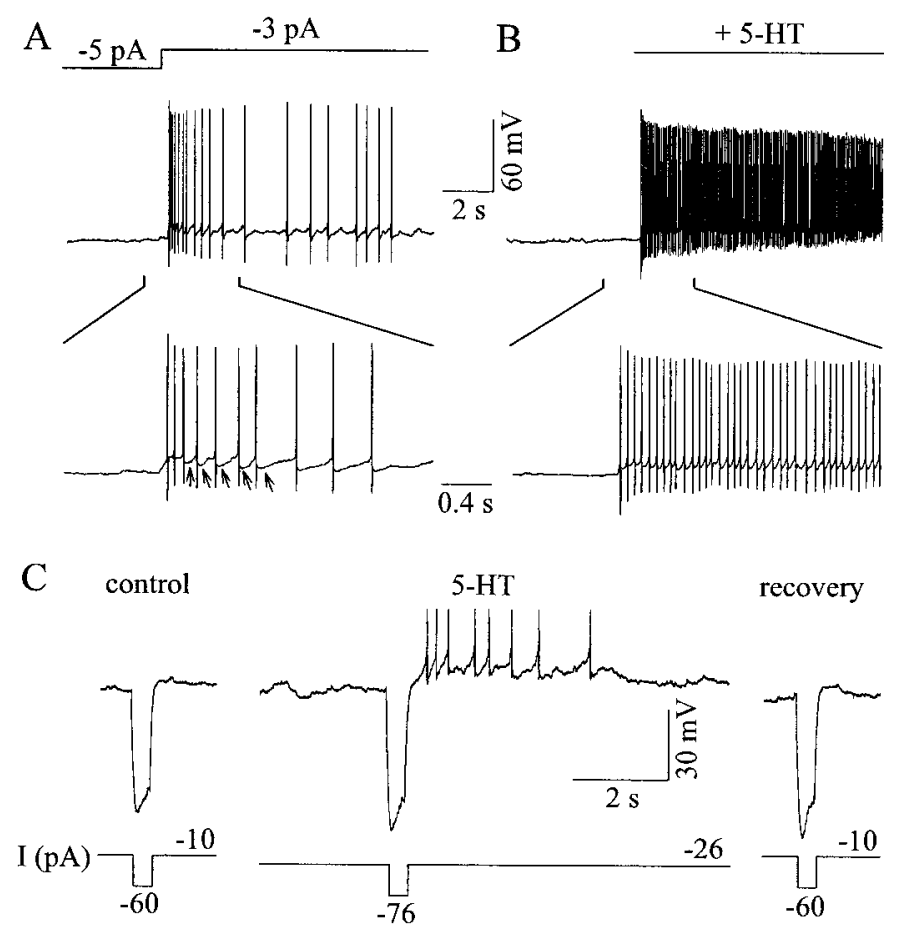

recovery
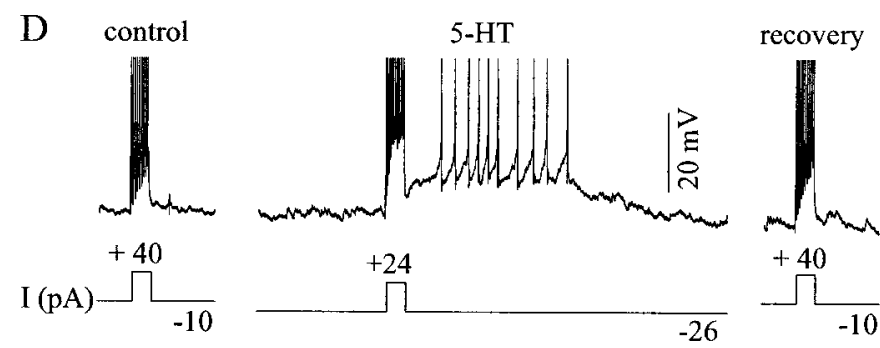

Figure 6. Mechanisms involved in serotonin excitation of Lugaro cells. $A$, Moderate depolarizing current pulses evoked Lugaro cell firing with a strong accommodation of the firing frequency. Note that the slow AHP is gradually developing (arrows) at the beginning of the spike train and causes accommodation. $B$, In the same cell, serotonin induced a moderate depolarization and sustained firing without accommodation. Note the small size of AHPs in the presence of serotonin. $C$, Effect of a $50 \mathrm{pA}$ hyperpolarizing current pulse before, during, and after application of serotonin in another cell. During serotonin application the holding current was changed to return to the resting potential recorded before serotonin application. Note the depolarizing plateau at the offset of the hyperpolarizing pulse in the presence of serotonin. $D$, Same as $C$, for 50 $\mathrm{pA}$ depolarizing pulses. Note the increased firing frequency and decreased AHPs during the depolarizing pulse. A depolarizing plateau is also present at the offset of depolarizing pulses in the presence of serotonin.

depolarization mediated by $I_{\mathrm{h}}$ in thalamic neurons (Lüthi and McCormick, 1999).

\section{Organization of the Lugaro cell axonal plexus}

The observation of biocytin-filled Lugaro cells confirmed previous data concerning the organization of its axons (Fig. $5 A$ ). It is commonly accepted that the Lugaro cell has a parasagittally oriented thin varicose axon (Lugaro, 1894; Ramón y Cajal, 1911; Fox, 1959; Palay and Chan-Palay, 1974; Lainé and Axelrad, 1996). This axon originates from the cell body, and although it may run for some distance in the granular layer, it always ascends back to the molecular layer (Lainé and Axelrad, 1996) where it makes synaptic contacts (Lainé and Axelrad, 1998). This parasagittal 
Figure 7. Calretinin immunoreactivity of Lugaro cells in the parasagittal $(A, B)$, coronal $(C 1, C 2)$, or transverse plane $(D, E)$ of the rat cerebellum. $A$, Low-magnification reconstruction of a lobule in the sagittal plane. Lugaro cell bodies (arrows) are located beneath the Purkinje cell layer; their dendrites remain in the upper granule cell layer or at the border of the Purkinje cell layer. $B$, High magnification of a Lugaro cell body, located between two Purkinje cell bodies that are immunonegative for calretinin. Two dendrites (arrows) originate from the opposite poles of the typically fusiform cell body. Immunoreactive spots ( $a r$ rowheads) corresponding to Lugaro axonal fibers, transversally cut, are observed above the Purkinje cell bodies in the sagittal plane. $C 1, C 2$, Lugaro cell dendrites and transverse axon collaterals are orthogonally orientated. Example of a Lugaro cell (asterisk) detected in the coronal plane when focused below the Purkinje cell layer $(C 1)$ or above it $(C 2)$. $C 1$, The initial segment of a dendrite bifurcates, and dendrites (arrows) coursing amid the Purkinje cell bodies are visible. $C 2$, Same region as in $C 1$, but focused at a level tangential to the low molecular layer. Dendrites are no longer visible, and varicose axons with a transverse course (arrowheads) are detected. Because of the curvature of the lobule, the cell body present in $C 1$ is still detected in C2 (asterisk). D, Lowmagnification reconstruction of a lobule in the transverse plane. Three Lugaro cell bodies are present (arrows). Calretinin-positive Lugaro axonal fibers follow a transverse course (arrowheads) in the low molecular layer. Note the calretinin background staining in the upper molecular layer (asterisk). E, Calretinin-positive axonal fibers in the low molecular layer, at high magnification. Most of the fi-
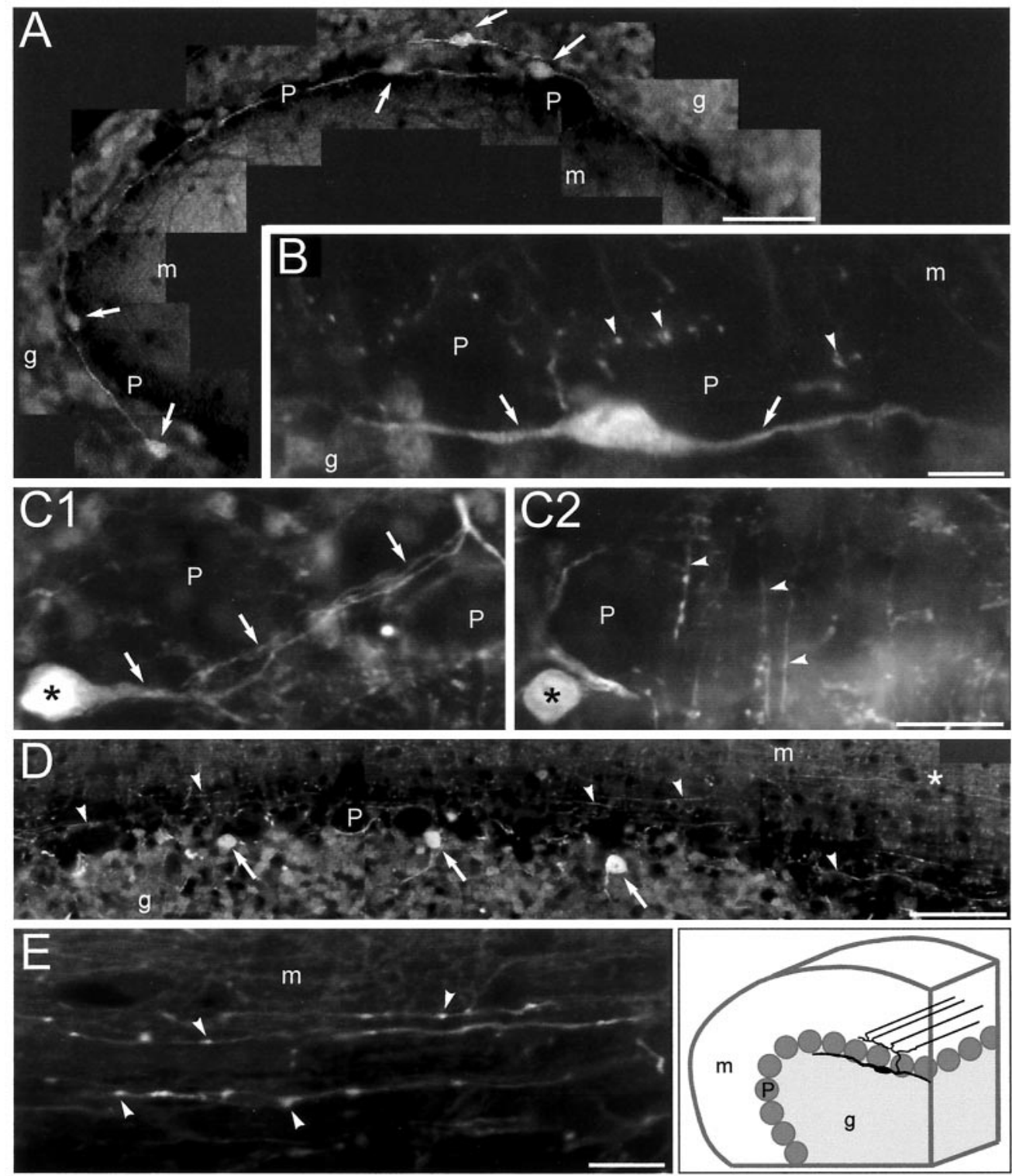
bers display immunoreactive varicosi-

ties (arrowheads). The inset shows a recapitulative drawing of a lobule cut in the sagittal plane, where a Lugaro cell has been represented in black. Four transverse axon collaterals are represented in the transverse orientation, which is the orientation of the parallel fibers. $m$, Molecular layer; $P$, Purkinje cell body; $g$, granule cell layer. Scale bars: $A, D, 50 \mu \mathrm{m} ; B, E, 10 \mu \mathrm{m} ; C 1, C 2,20 \mu \mathrm{m}$.

axon was found in many of the biocytin-filled Lugaro cells studied here and is illustrated in Figure $5 A$. Recent data suggest that this parasagittal axonal plexus contacts preferentially basket and stellate cells (Lainé and Axelrad, 1998). This inhibitory connection may account for the slow serotonin-induced reduction in IPSC frequency recorded from Purkinje cells (Fig. 4).

Some authors have also proposed that Lugaro cells have a transverse axonal plexus in the form of thick axonal branches that extend in the axis of the folia, parallel to the parallel fibers (Lugaro, 1894; Fox, 1959; Lainé and Axelrad, 1996). The infrequent staining of these branches in Golgi preparations has cast a doubt on their morphological relevance. In the cell of Figure $5 A$, two transverse axonal branches arose from the main parasagittal plexus. One of them $(\downarrow)$ was cut at the surface and reached the main plexus after a course of $30 \mu \mathrm{m}$, whereas the other $(\boldsymbol{\nabla})$ ran toward the depth of the slice but could not be followed for more than $25 \mu \mathrm{m}$. A third transverse neurite $(-)$ originated from a dendrite at a depth of $40 \mu \mathrm{m}$ and ran in the molecular layer toward the surface of the slice, where it was cut. The latter type of neurite was seen in other Lugaro cells, and in one case it could be followed through the whole thickness of the slice $(200 \mu \mathrm{m})$. The diameter of these neurites $(\sim 1 \mu \mathrm{m})$ corresponds to the diameter of the calretinin-positive axons described below. The Lugaro cell might therefore be a multiaxonal neuron.

To further study the distribution and morphology of Lugaro cells, we took advantage of the fact that calretinin strongly stains unipolar brush cells (UBCs) and Lugaro cells in the cerebellar cortex (Rogers, 1989). UBCs, whose axons remain in the granule cell layer, were unambiguously identified by their peculiar dendritic morphology (Mugnaini and Floris, 1994). The cell bodies and dendrites of Lugaro cells were easily recognized under the Purkinje cell layer in parasagittal sections (Fig. $7 A, B$ ). The para- 

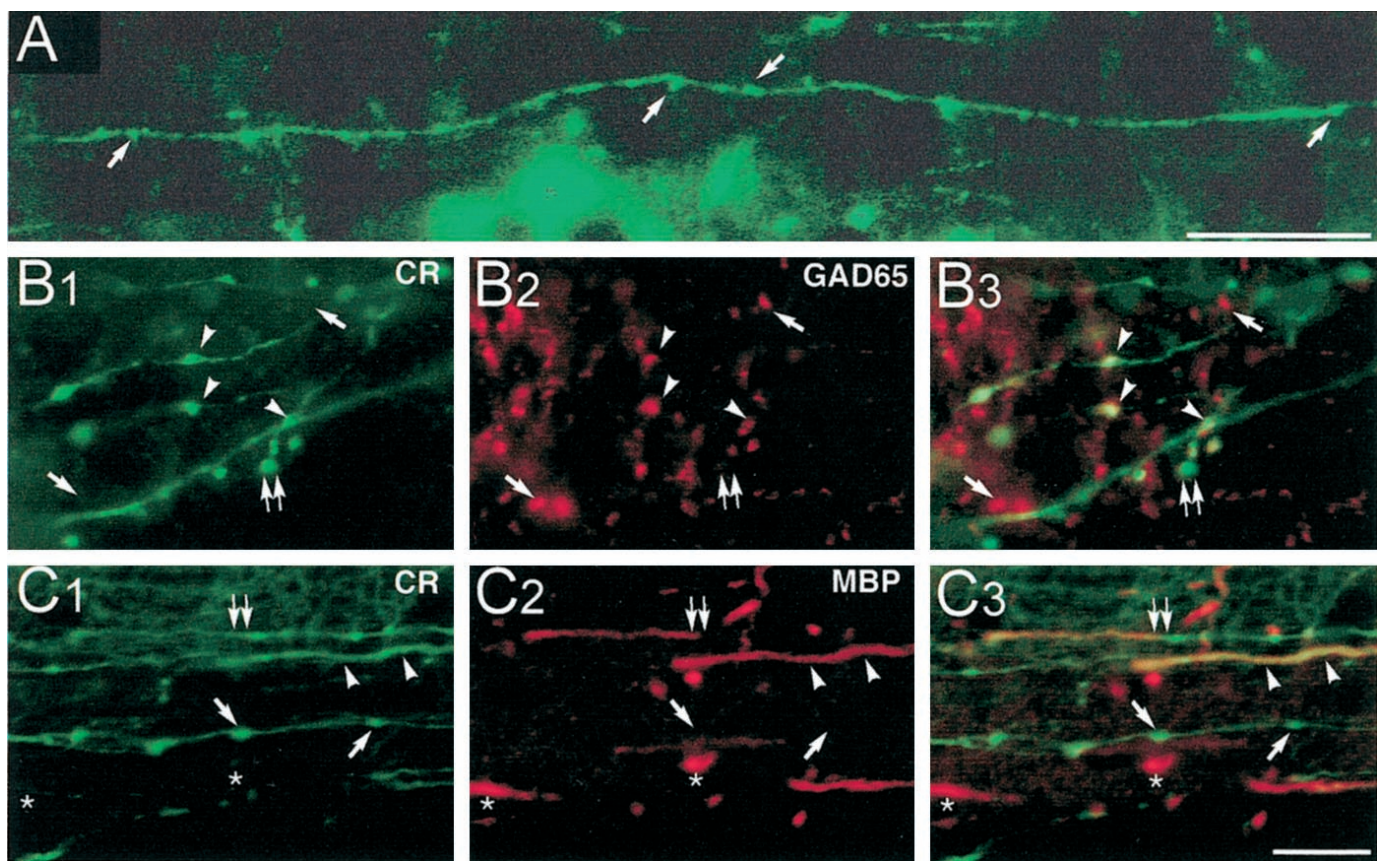

Figure 8. Lugaro cell axons in the transverse plane. $A$, Segment of a Lugaro cell axon stained for calretinin that could be followed for $>350 \mu$ m. $B$, $C$, Sections were double-stained with anti-calretinin antibody (green in B1 and C1) and anti-GAD65 (red in B2) or anti-MBP (red in C2). B3 and C3 are the superimposed images $B 1-B 2$ and $C 1-C 2 . B$, Axonal varicosities immunoreactive for calretinin are positive for GAD65 (arrowheads), but the number of GAD65-containing terminals outnumbers the calretinin-positive varicosities (arrows). Some rare spots are calretinin positive and GAD65 negative (double arrow). C, Lugaro cell transverse axons are partially myelinated. Nonvaricose segments of calretinin-positive axons are myelinated (arrowhead), whereas varicose ones are not (arrows). Note that myelination stops (double arrow) in calretinin-positive fibers when the fiber starts to be varicose. Some MBP immunoreactivity is not associated with calretinin-labeled fibers (asterisks). Scale bars: $A, 30 \mu \mathrm{m} ; B, C, 10 \mu \mathrm{m}$.

sagittal plexus of the Lugaro axon was difficult to detect because of a background staining of the granular and molecular layers. This staining resulted from a low level of calretinin expression in the somatodendritic and axonal cytoplasm of granule cells and was always lower in the bottom third of the molecular layer. We quantified the total number of calretinin-positive Lugaro cell bodies in all the lobules of $30-\mu \mathrm{m}$-thick sections of the vermis and found an average of $99 \pm 8$ (mean \pm SEM; $n=5$; four animals) cell bodies per section. Lugaro cells were found equally frequently in all lobules, but their distribution was not homogeneous. Several (three to five) Lugaro cell bodies were often grouped in the curvature between lobules but were rarely found at the apex of the lobules. The developed longitudinal length of the Purkinje cell layer in the vermis was evaluated at $50 \mathrm{~mm}$, and thus the surface of this layer in the slices approximates $1.5 \mathrm{~mm}^{2}$. Given that a Purkinje cell occupies on average $0.001 \mathrm{~mm}^{2}$ (Harvey and Napper, 1991), the number of Purkinje cells in our slices was estimated to be 1500, and the ratio of the number of Lugaro cells per Purkinje cell was 1:15.

The Lugaro cells spatial organization was better appreciated in some areas of coronal slices, where the plane of cut was tangential to the bottom of the Purkinje cell layer (Fig. 7C1). Lugaro cell dendrites often deviated from their main parasagittal orientation to form X-shaped lattices centered on the Lugaro cell bodies. The dendrites formed a dense mesh around and under Purkinje cell bodies, and several dendrites coming from different cells were often found in tight apposition. When in the same observation field one focused on the bottom of the molecular layer, calretininimmunoreactive fibers were seen running perpendicularly to the main orientation of the Lugaro cell dendrites (Fig. 7C2). These fibers differed from dendrites by being straight and varicose in some portions. In transverse sections perpendicular to the plane of the Purkinje cell dendrites, these fibers were located in the low molecular layer, above the Purkinje cell bodies (Fig. 7D,E). These fibers differed from the parallel fibers (Harvey and Napper, 1991) by their larger diameter $(>1 \mu \mathrm{m})$ and may correspond to a previously identified minor population of large fibers running parallel to the parallel fibers in the lower molecular layer (Pichitpornchai et al., 1994). The thickest portion of these axons could easily be followed for hundreds of micrometers (Fig. 8A).

The varicosities of these calretinin-positive fibers were GAD65-positive (Fig. 8B), confirming that they are not parallel fibers but rather the axon of inhibitory Lugaro cells. GAD65 immunoreactivity was also found in terminals where it was not associated with calretinin. These terminals presumably correspond to the synapses made by basket cell axons and Purkinje cell recurrent collaterals in the low molecular layer. Colocalization of calretinin and MBP in transverse fibers indicated that the transverse plexus of Lugaro cell axons is myelinated in part. Thick unvaricose segments were most frequently myelinated, whereas segments bearing varicosities were not (Fig. $8 C$ ); the two types of immunoreactive pattern were often observed along the same axonal fiber. Because almost all of the MBP-positive axons were calretinin-positive, we may assume that at the age analyzed, Lugaro axons constitute the majority of myelinated fibers in the low molecular layer. The remaining myelinated fibers probably correspond to Purkinje cell recurrent collaterals (Hámori and Szentágothai, 1968; Palay and Chan-Palay, 1974; Lange, 1976, 1978). In conclusion, the transverse branches of the Lugaro cell axon form an inhibitory, partly myelinated plexus in the low molecular layer that is located adequately to form inhibitory contacts with Golgi cell apical dendrites crossing this region. 


\section{DISCUSSION}

\section{Serotonin excitation of Lugaro cells accounts for serotonin-driven IPSCs in Golgi cells}

We have shown that serotonin increases the frequency of IPSCs in Golgi cells. This serotonin-driven inhibitory activity arises from the excitation of a small number of presynaptic inhibitory interneurons, which differ from the interneurons responsible for background inhibition of Golgi cells by the amplitude of their IPSCs. We further show that Lugaro cells are selectively excited by serotonin in the slice. Although the connection between Lugaro and Golgi cells is not demonstrated directly in this work, the results that are presented strongly suggest that excitation of Lugaro cells by serotonin accounts for the serotonin-driven inhibitory activity recorded from Golgi cells. As discussed in Results, Golgi or Purkinje cells are not likely candidates, primarily because they do not appear to contact Golgi cells.

The case of molecular layer interneurons necessitates further comments. We report that serotonin induces a slight decrease in the amplitude and frequency of the IPSCs recorded from Purkinje cells. Our results appear to contradict those of Mitoma et al. (1994), who show that serotonin increases the amplitude and frequency of the IPSCs recorded from Purkinje cells, and other data showing that serotonin increases Purkinje cell responsiveness to GABA (Strahlendorf et al., 1989, 1991; Kerr and Bishop, 1992). These effects most likely involve a postsynaptic modulation of GABA receptors or of endogenous membrane conductances (Wang et al., 1992; Li et al., 1993). In our experiments the low access resistance, known to induce a fast washout of postsynaptic second messenger systems, together with the Cs-based internal solution used, which reduces potassium conductances, probably minimized postsynaptic effects of serotonin. In any case, if serotonin was able to induce spike firing in a subpopulation of basket or stellate cells, a large increase in IPSC frequency should still be seen in Purkinje cells in our experimental conditions. Because such an increase was not recorded, we conclude that modulation of basket and stellate cell firing is not responsible for the effect of serotonin on the inhibitory input to Golgi cells. Finally, given the existence of synaptic contacts between basket and Golgi cells, the spontaneous activity of basket cells in the slice probably accounts for the background serotonin-insensitive IPSCs recorded from Golgi cells.

The analysis developed in Results provides a number of positive arguments that point to Lugaro cells as the source of serotonin-driven inhibition of Golgi cells. Lugaro cells are usually silent in the slice. They are excited by serotonin at the same concentration that evokes IPSCs in Golgi cells, and the frequency of firing of Lugaro cells is in the same range as the frequency of serotonin-evoked IPSCs in Golgi cells. Serotonin suppresses the accommodation in the firing of Lugaro cells and transforms these cells into regular spiking neurons, in agreement with the rhythmic occurrence of serotonin-driven IPSCs in Golgi cells. Finally, Lugaro cells are not abundant, which would explain why in the slice a given Golgi cell receives the input of only one or two cells.

What are the likely hypotheses about the action of Lugaro cells' inhibitory input onto Golgi cells? The absence of effect of Lugaro cell inhibition on the basal firing frequency of Golgi cells suggests that these IPSPs do not significantly hyperpolarize Golgi cells (Dieudonné, 1998). It is possible that in the intact cerebellum, a given Golgi cell receives inputs from many Lugaro cells and that the combined action of these inputs has a significant hyperpolarizing effect. Another possibility is that the inhibition coming from
Lugaro cells is mainly implicated in the shunt of distal excitation (Lugaro cell synapses are appropriately located at the basis of the Golgi cells apical dendrites) or in the precise timing of the firing of action potentials by Golgi cells.

\section{Organization of the Golgi cell-Lugaro cell connection}

The cell reconstructions presented here demonstrate that the Lugaro cell possesses two axonal plexes. One ramifies in the parasagittal plane, as do most other neurites in the cerebellum, and the other consists of transversal fibers and represents, with the parallel fibers, the only pathway for transverse information flow in the cerebellar cortex. Immunohistochemical stainings reveal that these transverse Lugaro cell axons form a dense plexus in the lower third of the molecular layer. The myelination of this plexus and the large diameter of its fibers would allow a fast action potential conduction, suggesting that a precise timing of the Lugaro cell inhibition is important for cerebellar function. In adult animals, the Lugaro cell transverse axons can be very long: $2 \mathrm{~mm}$ in the cat (Lugaro, 1894) and at least $1.4 \mathrm{~mm}$ in the baboon (Fox, 1959). Our observations indicate that their length in rat is also in the millimeter range. A more precise value of $2 \mathrm{~mm}$ (half the length of the parallel fibers) can be taken from Pichitpornchai et al. (1994), who found a small subpopulation of thick fibers running parallel to the parallel fibers in the lower third of the molecular layer and emitting short lateral branches, as reported by Fox (1959) for Lugaro cell axons.

Electrophysiological data indicate that the transverse plexus of the Lugaro cell axons participates in the synaptic contacts made with Golgi cells. Lugaro cells used for direct recording, and located at the surface of the slice, respond to serotonin with a negligible latency. In contrast, the serotonin-induced increase of IPSC frequency recorded from Golgi cells has a long latency and progressive onset. In addition, when several presynaptic Lugaro cells are preserved in the slice, excitation of these cells by serotonin occurs with different latencies. This most likely indicates that when we recorded from Golgi cells, serotonin had to reach Lugaro cells located in the depth of the slice. Given the fact that Golgi cell dendrites are restricted to a narrow parasagittal volume (Dieudonné, 1998), connections between Lugaro cells deep in the parasagittal slices and Golgi cells located at the surface can be made only by the transverse axons of Lugaro cell.

Our data allow us to give lower estimates of the level of convergence $(C)$ and divergence $(D)$ of the Lugaro cell to Golgi cell connection, if they are made at random along the $2 \mathrm{~mm}$ of the Lugaro cell transverse axons. Because there was on average more than one presynaptic Lugaro cell per Golgi cell in parasagittal slices of $200 \mu \mathrm{m}$ thickness, each Golgi cell may be contacted by $>10$ Lugaro cells in the intact cerebellum. Because the total number $(N)$ of connected Lugaro-Golgi pairs is given by $N=N_{\mathrm{G}}$ $\times C=N_{\mathrm{L}} \times D$, where $N_{\mathrm{G}}$ is the number of Golgi cells in the cerebellum and $N_{\mathrm{L}}$ is the number of Lugaro cells. It follows that an underestimate of the divergence $(D)$ is $D=C \times\left(N_{\mathrm{G}} / N_{\mathrm{L}}\right)$.

Our estimation of 1 Lugaro cell for 15 Purkinje cells is close to the 1:30 ratio obtained in the cat (Sahin and Hockfield, 1990), and the ratio of the number of Golgi cells relative to the number of Purkinje cells has been estimated to be close to one in the rat (Korbo et al., 1993). Therefore $N_{\mathrm{G}} / N_{\mathrm{L}}=15$, and the divergence $D$ is $>150$. This means that each Lugaro cell can affect the Golgi cell inhibitory input over large populations of granule cells.

Given the peculiar transverse organization of their axons, Lugaro cells might play a role in the synchrony found between the spikes of Golgi cells situated along the same parallel fiber beam 
(Vos et al., 1999). Because the divergence of the Lugaro cell to Golgi cell connection is high, the Lugaro cell may also participate in the large amplitude oscillations recorded in the granular layer of freely moving animals (Pellerin and Lamarre, 1997; Hartmann and Bower, 1998). These oscillations have a frequency similar to that of Lugaro cell firing $(\sim 7-15 \mathrm{~Hz})$ and can be synchronous along the whole length of the lobule.

\section{Modulation of Lugaro cells by serotonin in vivo}

The fact that Lugaro cell excitation and subsequent Golgi cell inhibition can be evoked by submicromolar concentrations of serotonin indicates that these effects are of physiological relevance. Indeed, the densest part of the serotoninergic plexus in the vermis corresponds to the location of the cell body and dendrites of the Lugaro cells (Chan-Palay, 1975; Bishop and Ho, 1985), which may allow a fast and preferential modulation of this cell type. Furthermore, microdialysis experiments have revealed that the level of serotonin in the cerebellar cortex is specifically and positively correlated to the level of motor activity of the animal (Mendlin et al., 1996). Combining retrograde tracing from the cerebellar cortex and serotonin immunohistochemistry experiments has shown that in any region of the brain stem a small percentage of the cells that are retrogradely labeled from the cerebellar cortex are immunoreactive for serotonin; the others are immunoreactive for glutamate (Bishop and Ho, 1985; Batini, 1993; Bishop et al., 1993). These data suggest that the glutamatergic input from precerebellar nuclei to the cerebellum is accompanied by a serotoninergic input that has the same topographical organization and that serotonin is released in the cerebellar cortex where and when mossy fibers afferents are active. The serotonin-induced bistability of Lugaro cells (Fig. 6B,C) may consequently allow small compartments of the cerebellar cortex to switch rapidly from one mode of computation to another, just when and where a fine control of ongoing movement is needed.

\section{REFERENCES}

Batini C (1993) The cerebellar projection from the neurons of the Raphe nuclei and the origin of the serotoninergic innervation of the cerebellum. In: Serotonin, the cerebellum, and ataxia (Trouillas P, Fuxe K, eds), pp 51-61. New York: Raven.

Bishop GA, Ho RH (1985) The distribution and origin of serotonin immunoreactivity in the rat cerebellum. Brain Res 331:195-207.

Bishop GA, Kerr CW (1992) The physiological effects of peptides and serotonin on Purkinje cell activity. Prog Neurobiol 39:475-492.

Bishop GA, Kerr CW, Chen YF, King JS (1993) The serotoninergic system in the cerebellum: origin, ultrastructural relationships, and physiological effects. In: Serotonin, the cerebellum, and ataxia (Trouillas P, Fuxe K, eds), pp 91-112. New York: Raven.

Chan-Palay V (1975) Fine structure of labelled axons in the cerebellar cortex and nuclei of rodents and primates after intraventricular infusions with tritiated serotonin. Anat Embryol 148:235-265.

Darrow EJ, Strahlendorf HK, Strahlendorf JC (1990) Response of cerebellar Purkinje cells to serotonin and the $5-\mathrm{HT}_{1 \mathrm{~A}}$ agonists $8-\mathrm{OH}-$ DPAT and ipsapirone in vitro. Eur J Pharmacol 175:145-153.

Dieudonné S (1995) Glycinergic synaptic currents in Golgi cells of the rat cerebellum. Proc Natl Acad Sci USA 92:1441-1445.

Dieudonné S (1998) Submillisecond kinetics and low efficacy of parallel fibre-Golgi cell synaptic currents in the rat cerebellum. J Physiol (Lond) 510:845-866.

Eccles JC, Ito M, Szentagothai J (1967) The cerebellum as a neuronal machine. New York: Springer-Verlag.

Fox CA (1959) The intermediate cells of Lugaro in the cerebellar cortex of the monkey. J Comp Neurol 112:39-51.

Gottlieb DI, Chang YC, Schwob JE (1986) Monoclonal antibodies to glutamic acid decarboxylase. Proc Natl Acad Sci USA 83:8808-8812.

Groome NP, Dawkes A, Gales M, Hruby S, Alvord ECJ (1986) Region- specific immunoassays for human myelin basic protein. Neuroimmunology 12:253-264.

Hámori J, Szentágothai J (1968) Identification of synapses formed in the cerebellar cortex by Purkinje axon collaterals: an electron microscope study. Exp Brain Res 5:118-128.

Hartmann MJ, Bower JM (1998) Oscillatory activity in the cerebellar hemispheres of unrestrained rats. J Neurophysiol 80:1598-1604.

Harvey RJ, Napper RMA (1991) Quantitative studies on the mammalian cerebellum. Prog Neurobiol 36:437-463.

Hicks TP, Krupa M, Crépel F (1989) Selective effects of serotonin upon excitatory amino acid-induced depolarizations of Purkinje cells in cerebellar slices from young rats. Brain Res 492:371-376.

Hounsgaard J, Kiehn O (1989) Serotonin-induced bistability of turtle motoneurones caused by a nifedipine-sensitive calcium plateau potential. J Physiol (Lond) 414:265-282.

Hounsgaard J, Hultborn H, Jespersen B, Kiehn O (1988) Bistability of $\alpha$-motoneurones in the decerebrate cat and in the acute spinal cat after intravenous 5-hydroxytryptophan. J Physiol (Lond) 405:345-367.

Jacobs BL, Fornal CA (1997) Serotonin and motor activity. Curr Opin Neurobiol 7:820-825.

Kerr CW, Bishop GA (1992) The physiological effects of serotonin are mediated by the $5 \mathrm{HT}_{1 \mathrm{~A}}$ receptor in the cat's cerebellar cortex. Brain Res 591:253-260.

Korbo L, Andersen BB, Ladefoged O, Moller A (1993) Total numbers of various cell types in rat cerebellar cortex estimated using an unbiased stereological method. Brain Res 609:262-268.

Lainé J, Axelrad H (1996) Morphology of the Golgi-impregnated Lugaro cell in the rat cerebellar cortex: a reappraisal with a description of its axon. J Comp Neurol 375:618-640.

Lainé J, Axelrad H (1998) Lugaro cells target basket and stellate cells in the cerebellar cortex. NeuroReport 9:2399-2403.

Lange W (1976) The myelinated parallel fibers of the cerebellar cortex and their regional distribution. Cell Tissue Res 166:489-496.

Lange W (1978) The myelination of the cerebellar cortex in the cat. J Neurophysiol 41:654-676.

Larramendi LM, Lemkey-Johnston N (1970) The distribution of recurrent Purkinje collateral synapses in the mouse cerebellar cortex: an electron microscopic study. J Comp Neurol 138:451-459.

Li SJ, Wang Y, Strahlendorf HK, Strahlendorf JC (1993) Serotonin alters an inwardly rectifying current $\left(I_{\mathrm{h}}\right)$ in rat cerebellar Purkinje cells under voltage clamp. Brain Res 617:87-95.

Llano I, Marty A, Armstrong CM, Konnerth AM (1991) Synaptic- and agonist-induced excitatory currents of Purkinje cells in rat cerebellar slices. J Physiol (Lond) 434:183-213.

Llinás R, Sugimori M (1980) Electrophysiological properties of in vitro Purkinje cell somata in mammalian cerebellar slices. J Physiol (Lond) 305:171-195.

Lu H, Larson-Prior LJ (1996) Serotoninergic modulation of evoked responses in turtle cerebellar Purkinje cells. J Neurophysiol 76:3102-3113.

Lugaro E (1894) Sulle connessioni tra gli elemente nervosi della corteccia cerebellare con considerazioni generali sulsignificato fisiologico dei rapporti tra gli elementi nervosi. Rivista Sperimentale di Freniatria 20: 297-331.

Lüthi A, McCormick DA (1999) Modulation of a pacemaker current through $\mathrm{Ca}^{2+}$-induced stimulation of cAMP production. Nat Neurosci 2:634-641.

Maura G, Raiteri M (1996) Serotonin 5-HT $\mathrm{HD}_{1 \mathrm{D}}$ and 5-HT $1 \mathrm{~A}$ receptors respectively mediate inhibition of glutamate release and inhibition of cyclic GMP production in rat cerebellum in vitro. J Neurochem 66:203-209.

Maura G, Carbone R, Guido M, Pestarino M, Raiteri M (1991) 5- $\mathrm{HT}_{2}$ presynaptic receptors mediate inhibition of glutamate release from cerebellar mossy fibre terminals. Eur J Pharmacol 202:185-190.

Mendlin A, Martín FJ, Rueter LE, Jacobs BL (1996) Neuronal release of serotonin in the cerebellum of behaving rats: an in vivo microdialysis study. J Neurochem 67:617-622.

Mitoma H, Kobayashi T, Song SY, Konishi S (1994) Enhancement by serotonin of GABA-mediated inhibitory synaptic currents in rat cerebellar Purkinje cells. Neurosci Lett 173:127-130.

Mugnaini E, Floris A (1994) The unipolar brush cell: a neglected neuron of the mammalian cerebellar cortex. J Comp Neurol 339:174-180.

Netzeband JG, Weathers LB, Strahlendorf HK, Strahlendorf JC (1993) Serotonin depresses excitatory amino acid-induced excita- 
tion of cerebellar Purkinje cells in the adult rat in vivo. Brain Res 608:145-149.

Palay SL, Chan-Palay V (1974) Cerebellar cortex: cytology and organisation. Berlin: Springer.

Pellerin JP, Lamarre Y (1997) Local field potential oscillations in primate cerebellar cortex during voluntary movement. J Neurophysiol 78:3502-3507.

Pichitpornchai C, Rawson JA, Rees S (1994) Morphology of parallel fibres in the cerebellar cortex of the rat: an experimental lightand electron microscopic study with biocytin. J Comp Neurol 342:206-220.

Raiteri M, Maura G, Bonanno G, Pittaluga A (1986) Differential pharmacology and function of two 5- $\mathrm{HT}_{1}$ receptors modulating transmitter release in rat cerebellum. J Pharmacol Exp Ther 237:644-648.

Ramón y Cajal S (1911) Histologie du système nerveux de l'homme et des vertébrés. Paris: Maloine.

Rogers JH (1989) Immunoreactivity for calretinin and other calciumbinding proteins in cerebellum. Neuroscience 31:711-721.

Sahin M, Hockfield S (1990) Molecular identification of the Lugaro cell in the cat cerebellar cortex. J Comp Neurol 301:575-584.
Strahlendorf JC, Lee M, Netzeband JG, Strahlendorf HK (1988) Pentobarbital augments serotonin-mediated inhibition of cerebellar purkinje cells. Neuroscience 27:107-115.

Strahlendorf JC, Lee M, Strahlendorf HK (1989) Modulatory role of serotonin on GABA-elicited inhibition of cerebellar Purkinje cells. Neuroscience 30:117-125.

Strahlendorf JC, Lee M, Strahlendorf HK (1991) Serotonin modulates muscimol- and baclofen-elicited inhibition of cerebellar Purkinje cells. Eur J Pharmacol 201:239-242.

Trouillas P, Fuxe K (1993) Serotonin, the cerebellum and ataxia. New York: Raven.

Ungerstedt U (1971) Stereotaxic mapping of the monoamine pathways in the rat brain. Acta Physiol Scand Suppl 367:1-48.

Vos BP, Maex R, Volny-Luraghi A, De Schutter E (1999) Parallel fibers synchronize spontaneous activity in cerebellar Golgi cells. J Neurosci 19:RC6.

Wang Y, Strahlendorf JC, Strahlendorf HK (1992) Serotonin reduces a voltage-dependent transient outward potassium current and enhances excitability of cerebellar Purkinje cells. Brain Res 571:345-349. 